\title{
LOURNAL.RU
}

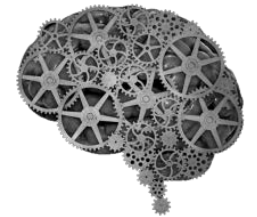

COMPANY GROUP "INTELLEKT"

\author{
Назмутдинов А. $\Phi .{ }^{1}$, Назмутдинов Ас. $\Phi .{ }^{2}$ \\ ${ }^{1}$ OОO «Гапромнефть-НТЦ» \\ Санкт-Петербург, Россия \\ ${ }^{2}$ Московский государственный университет \\ Москва, Россия
}

doi: 10.18411/lj2016-6-2-11

\section{Установления равновесия жидкости и газа в замкнутом объеме}

Имеется замкнутая теплоизолированная емкость постоянного объема $(V)$. В емкости находится жидкий пропан и вода (в совокупности занимают объем $V_{0}$ ) при определенной температуре $\left(T_{0}\right)$. Над жидкостями - вакуум.. Нижние индексы: l соответствует жидкому пропану, g - газообразному пропану, w жидкой воде и v - пару воды.

Рассматривается процесс перехода системы к равновесию. Данный процесс описывается уравнение теплового баланса [1-9]:

$$
\dot{m}_{l} r_{l}+\dot{m}_{w} r_{w}+m_{l} c_{p l} \frac{d T}{d t}+m_{g} c_{v g} \frac{d T}{d t}+m_{v} c_{v v} \frac{d T}{d t}+m_{w} c_{p w} \frac{d T}{d t}=0,
$$

где $\dot{m}_{j}=-\frac{d m_{j}}{d t}-$ скорость испарения $j$ - го вещества; $r_{j}-$ удельная (скрытая) теплота парообразования $j$ - го вещества; $c_{v j}-$ теплоемкость $j-$ го газа (при $V=$ const), $c_{p j}-$ теплоемкость $j-$ й жидкости (при $p=$ const).

Это уравнение разрешается относительно $\frac{d T}{d t}$, добавив к уравнению баланса, уравнения скорости испарения, относительно 3-х ОДУ $\left(\frac{d T}{d t}, \frac{d m_{l}}{d t}, \frac{d m_{w}}{d t}\right)$, которая решается численно:

$$
\frac{d T}{d t}=\frac{-\left(\dot{m}_{l} r_{l}+\dot{m}_{w} r_{w}\right)}{m_{l} c_{p l}+\left(m_{l 0}-m_{l}\right) c_{v g}+\left(m_{w 0}-m_{w}\right) c_{v v}+m_{w} c_{p w}},
$$




$$
\begin{gathered}
\frac{d m_{l}}{d t}=-\dot{m}_{l}=\alpha_{l}\left(p_{l}^{*}-p_{l}\right), \\
\frac{d m_{w}}{d t}=-\dot{m}_{w}=\alpha_{w}\left(p_{v}^{*}-p_{v}\right),
\end{gathered}
$$

при выполнении уравнения состояния: $p_{j}=\rho_{j} R_{j}(T+273.15) \quad$ Клапейрона и закона Дальтона: $p=p_{v}+p_{g}$ (где $p_{v}$ и $p_{g}-$ парциальные давления).

Жидкости считаются несжимаемыми, т.е. $\rho_{l}=$ const, $\rho_{w}=$ const; $c_{v v}=$ $c_{v v}(p, T)=\left(c_{p v}(p, T)-R_{v}\right)-$ аппроксимируется многочленом 2-го порядка по $p$, коэффициенты которого аппроксимируются многочленом 2-го порядка по Т; остальные теплоемкости аппроксимированы для некоторого фиксированного значения $p$ линейной функцией: $c_{p w}=c_{p w}(T), c_{v g}=c_{v g}(T)=\left(c_{p g}(T)-\right.$ $\left.R_{g}\right), c_{p l}=c_{p l}(T) ;$ удельная теплота парообразования аппроксимирована для некоторого $p$ многочленами 2-го порядка: $r_{l}=r_{l}(T), r_{w}=r_{w}(T)$; давление насыщенных паров пропана аппроксимировано по формуле Антуана $\ln p^{*}(T)=$ $A-\frac{B}{T+273.15+C}$ (мм рт.ст.), где $A, B, C$ - табличные данные; давление насыщенных паров воды, как и в случае, описанном выше, найдены более точной формулой.

При расчетах использовались следующие формулы:

$$
\begin{gathered}
c_{p v}(T, p)=\left[\left(0.000000012688374 * T^{2}-0.000010323694739 * T+0.002132674736069\right) *\right. \\
* p^{2} / / 10^{10}+\left(-0.000000105361647 * T^{2}+0.000024603860694 * T+0.013223331613543\right) *
\end{gathered}
$$

$\left.{ }^{*} p / 10^{5}++\left(0.000000175596031 * T^{2}+0.000517190163502 * T+1.826753648960001\right)\right] *$

*1000Дж/кг*град,

$$
\begin{gathered}
c_{p w}(T)=(-0,0014 * T+2.6464) * 1000+1500 Д ж / к г * г р а д, \\
c_{p l}(T)=(0.0022 * T+2.2863) * 1000 Д ж / к г * г р а д, \\
c_{p g}(T)=(2.1744+0.0017 * T) * 1000+2000 Д ж / к г * г р а д, \\
r_{l}(T)=\left(-0.014 * T^{2}-1.79 * T+387.3\right) * 1000 Д ж / к г, \\
r_{w}(T)=\left(-0,015 * T^{2}+0.763 * T+2398\right) * 1000 Д ж / к г .
\end{gathered}
$$


Использованы те же выражения для давления насыщенных паров.

В выражениях $\dot{m}_{j}=-\alpha_{j}\left(p_{j}^{*}-p_{j}\right) \quad \alpha_{j}=$ const $>0$, причем, от величины этих констант зависит только скорость выхода на равновесия, поэтому, их выбор был обусловлен физичностью процесса.

На Рис.1-4 представлены результаты расчетов при различных исходных параметрах.

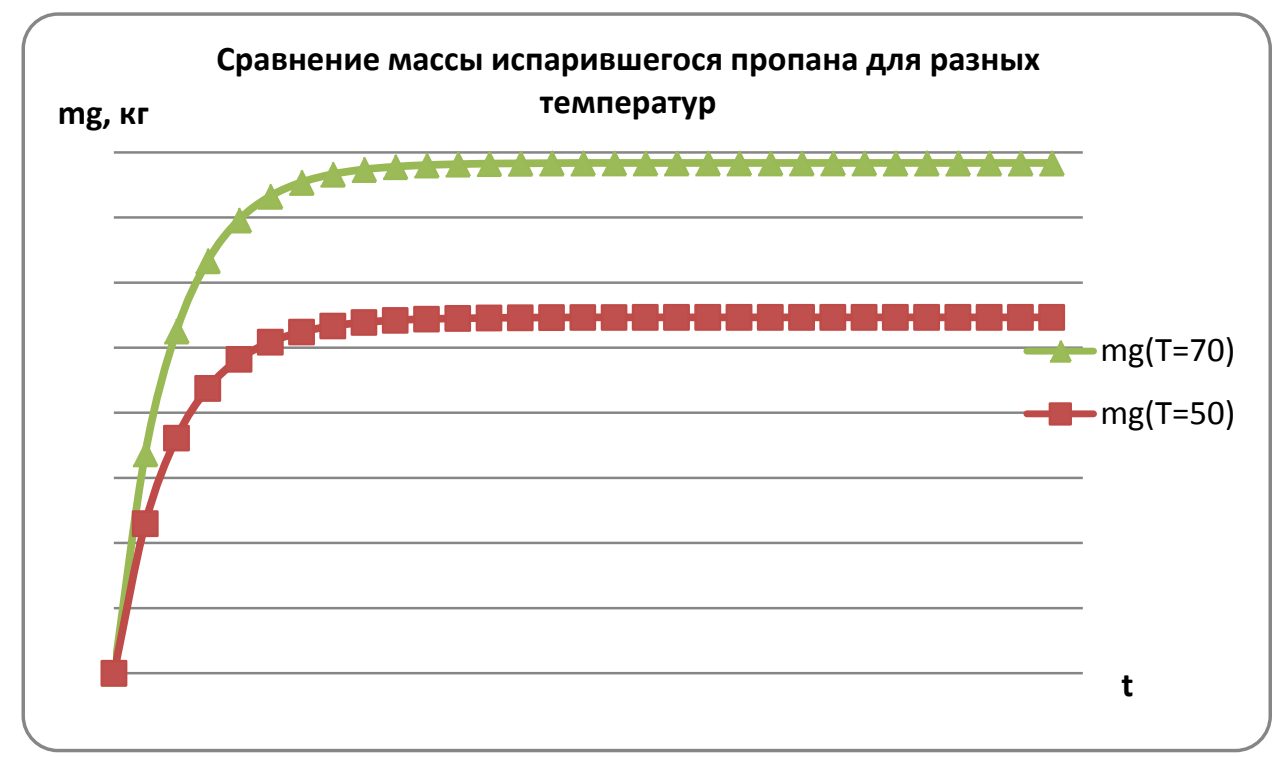

Puc.1

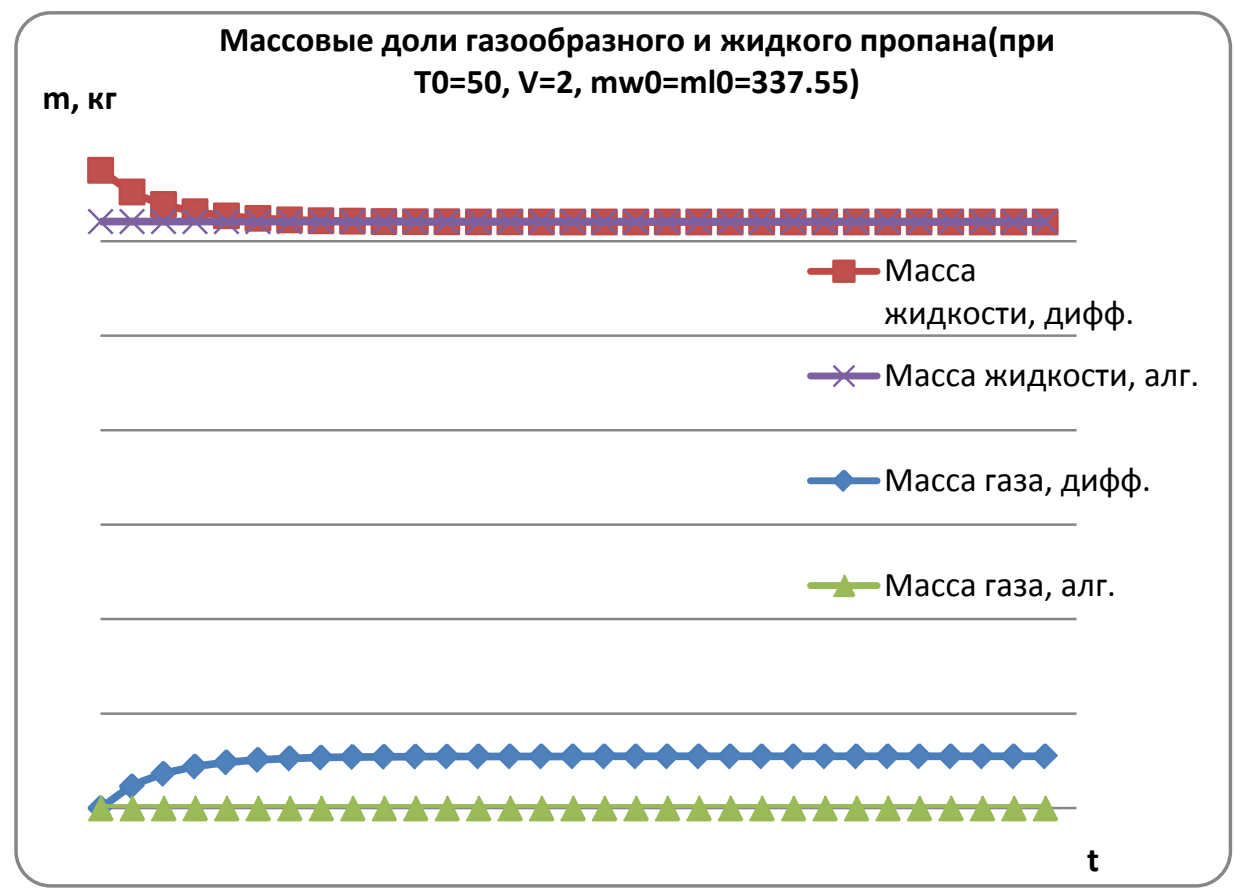


Puc. 2

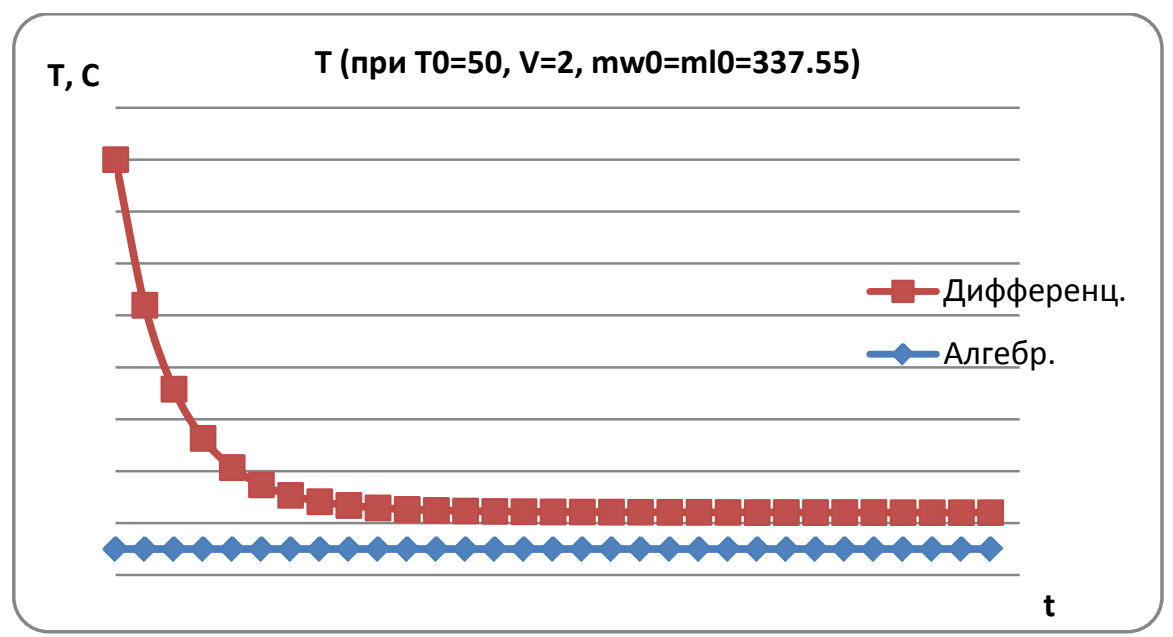

Puc.3

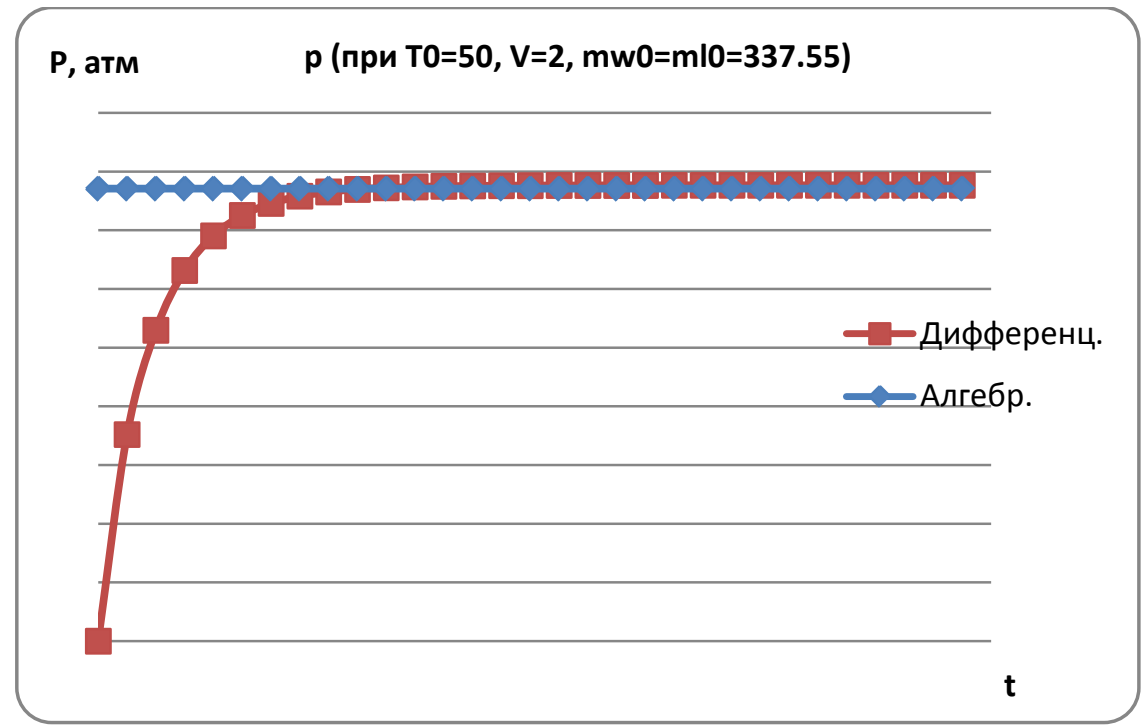

Puc. 4

Полученные результаты позволяют определить темп, конечное значение и особенности перехода системы к равновесию. 


\section{Литература:}

1. Назмутдинов А.Ф., Назмутдинова Л.Р. Особенности движения частиц по окружности со столкновениями. В сборнике: Актуальные вопросы современных математических и естественных наук. Сборник научных трудов по итогам международной научно-практической конференции. 2016. C. $16-18$

2. Reid R., Prausnitz J., Sherwood T. The Properties of Gases and Liquids. 1982.

3. Х Хабибуллин И.Л., Хамитов А.Т., Назмутдинов Ф.Ф. Особенности тепло- и массопереноса в пористых средах при фазовых превращениях при электромагнитном нагреве. В сборнике: Основные проблемы естественных и математических наук Сборник научных трудов по итогам международной научно-практической конференции. Инновационный центр развития образования и науки. 2014. С. 23-26.

4. World Meteorological Organization. Guide to Meteorological Instruments and Methods of Observation. 2008.

5. Назмутдинова Л.Р., Назмутдинов Ф.Ф. Модель высокочастотного электромагнитного воздействия на кинетику химических реакций. Теоретические и прикладные аспекты современной науки. 2015. № 8-1. С. 20-23

6. Хабибуллин И.Л., Хамитов А.Т., Назмутдинов Ф.Ф. Исследование динамики фазовых переходов в пористых средах, инициируемых нагревом электромагнитным излучением. Вестник Нижегородского университета им. Н.И. Лобачевского. 2011. № 4-5. С. 2556-2557.

7. Khabibullin I.L., Khamitov A.T., Nazmutdinov F.F. Modeling of heat and mass transfer in porous media at phase transitions initiated by microwave heating. High Temperature. 2014. V. 52. № 5. pp. 697-702.

8. Хабибуллин И.Л., Назмутдинов Ф.Ф. К теории нагрева сред электромагнитным излучением. Вестник Башкирского университета. 2014. T. 19. № 2. C. 381-384.

9. Nazmutdinov, F.F., Khabibullin, L.I. Mathematical modeling of gas desorption from a gas hydrate 